\title{
Reassessing volatile and trace element mobility at Mount St. Helens (2004-2008) from amphibole and melt inclusion geochemistry
}

\author{
T.R.HAMPEL*, M.C. ROWE ${ }^{2}$ A.J.R KENT. ${ }^{3}$
}

*1150 Gabrielle Elaine Dr. Apartment 110, Columbus, $\mathrm{OH}$ 43228 [timothyhampel@gmail.com]

${ }^{2}$ School of Environment, University of Auckland, Auckland 1010, New Zealand

[Michael.rowe@auckland.ac.nz]

${ }^{3}$ College of Earth, Ocean and Atmospheric Sciences, Oregon State University, Corvallis, OR 97331

[Adam.kent@geo.oregonstate.edu]

Volatile exsolution is an improtant process in volcanic systems. Prior studies have argued mineral geochemistry preserves evidence of volatile element mobility, based on enrichments and depletions inconsistent with mineral $/$ melt partitioning. Utilizing amphibole and amphibole-hosted melt inclusions, the goal of this study is to better understand the processes by which Li and select trace elements are coupling with magmatic volatiles $\mathrm{F}$ and $\mathrm{Cl}$ during transport through the Mount St. Helens magmatic system associated with the eruption of 2004-2008. To reassess these processes, the trace elements and metals in amphibole are compared to eruption dates, $\mathrm{P}$ and $\mathrm{T}$ of crystallization, structural data, experimental and published parition coeffients. We propose an updated model that incorporates all available mineral data from this eruption.

Comparing amphibole chlorine contents to $\mathrm{T}$ and $\mathrm{P}$ reveals two trends, with $\mathrm{Cl}$ both increasing and decreasing relative to changes in $\mathrm{T}$ and $\mathrm{P}$. With respect to the amphib ole phenocrysts, $\mathrm{Cl}$ abundances compared to $\mathrm{Zr}, \mathrm{Sn}, \mathrm{Zn}$ and $\mathrm{REE}$ also reveal two trends. In contrast, $\mathrm{Li}$ is not correlated to other trace elements in amphibole. In the melt inclusions $\mathrm{Zn}, \mathrm{Sr}$, and $\mathrm{Y}$ are broadly correlated to Li.

Incorporating these results with mineral-melt and meltfluid literature data, suggests that $\mathrm{Li}$ and $\mathrm{Cu}$, elements previously thought to exsolve at depth and partition into a fluid phase as the magma decompresses, are likely to stay in the melt. Similarly, chlorine behaves as an incompatible element in this system. Thus, trace elements and metals correlating to $\mathrm{Cl}$ will behave similarly. Although fluorine plays a critial role in stabalizing amphibole at lower pressures and temperatures in this system, it does not appear to play a critical role in the potential mobility of trace elements and trace metals. 